Portland State University

PDXScholar

\title{
Grieving Through Day of the Dead: the Influence of Culture on Processes and Resources
}

Sadie Layne Rockford

Portland State University

Follow this and additional works at: https://pdxscholar.library.pdx.edu/honorstheses

\section{Let us know how access to this document benefits you.}

\section{Recommended Citation}

Rockford, Sadie Layne, "Grieving Through Day of the Dead: the Influence of Culture on Processes and Resources" (2018). University Honors Theses. Paper 628.

https://doi.org/10.15760/honors.638

This Thesis is brought to you for free and open access. It has been accepted for inclusion in University Honors Theses by an authorized administrator of PDXScholar. Please contact us if we can make this document more accessible: pdxscholar@pdx.edu. 
Grieving Through Day of the Dead: The Influence of Culture on Processes and Resources

by

Sadie Layne Rockford

An undergraduate honors thesis submitted in partial fulfillment of the requirements for the degree of

Bachelor of Science

in

University Honors

and

Psychology/Sociology

Thesis Adviser

Dr. Tina Burdsall

Portland State University

2018 


\begin{abstract}
Day of the Dead is a festival that takes place in Mexico every year. The purpose of the festival is for loved ones to further mourn and honor their deceased. The festival includes many independently effective psychological components as well as beneficial sociological processes. The festival is an accurate reflection of the overall conceptualization of death and grief of Mexico's culture and history. This literature review analyzes how Day of the Dead further influences communities interactions with the expression of grief and the mourning process. Parson's sick role is used to analyze the expression of grief relative to social expectations, norms, and overall influence. The mourning process is conceptualized as a rite of passage in which people undergo transformation and growth as perceived by society and the individual. Day of the Dead re-affirms and maintains the culturally-relative effective beliefs, values, and behaviors that are observed in both the expression of grief and the mourning process in Mexico. It is a strong example of how the social structures and perceptions influence how people grieve death on individual and community levels. Day of the Dead should be recognized as an effective grieving resource, as it presents an annual celebratory context for active participants to further mourn together without the fear of negative social response.
\end{abstract}




\section{Table of Contents}

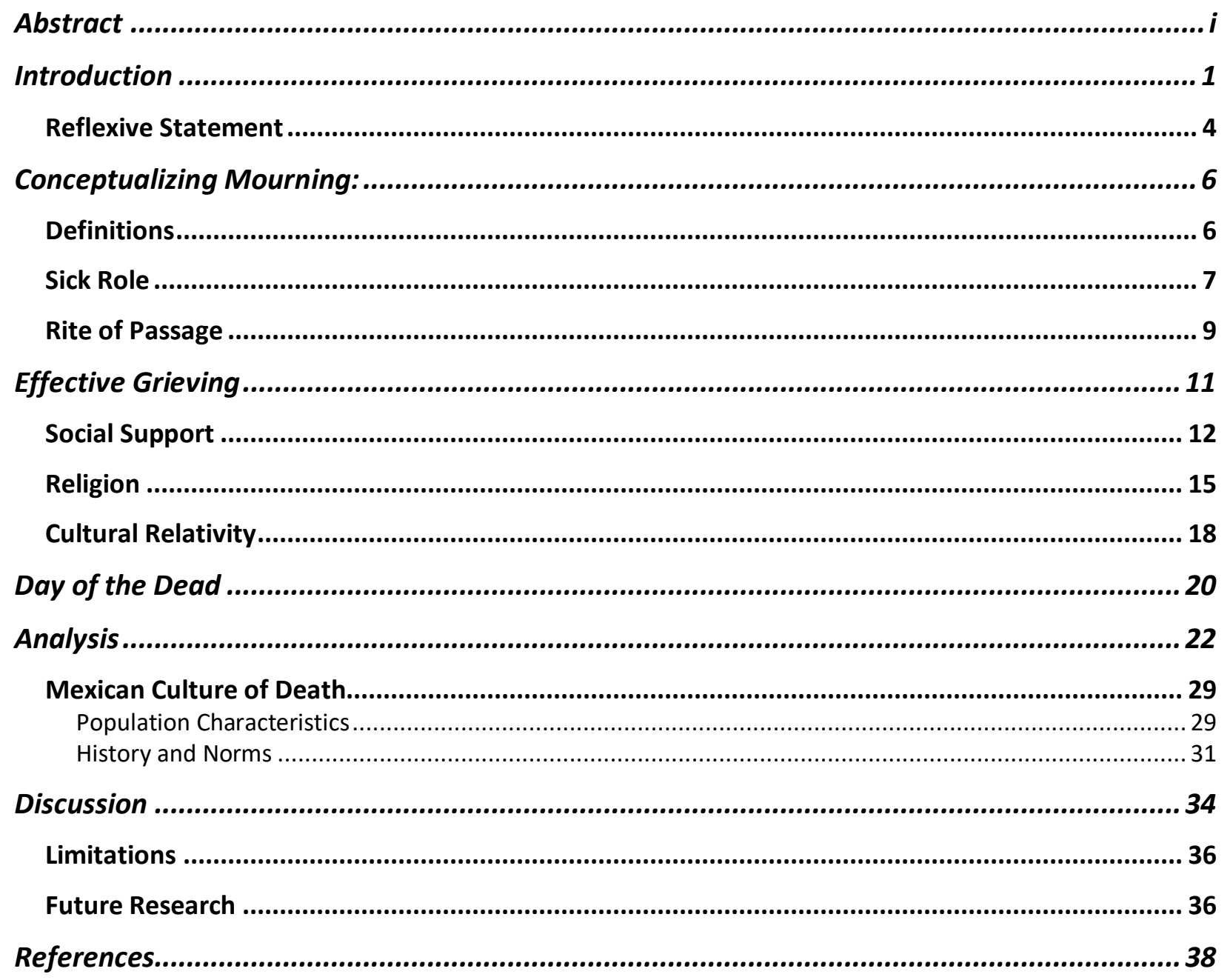





\section{Introduction}

The process of death and dying is something every human will experience. Grief is a natural response to death, the way it is manifested and expressed varies differently throughout the world. While the emotional response following a death is nearly universal, how we grieve is largely dependent on our culture and the different social circles we are a part of. There are numerous components to how people mourn, they often include specific rituals and traditions that influence our beliefs and conceptualizations of grief. It is important for us to have a deep understanding of how and why people grieve, so we can identify and improve the various resources and processes of mourning.

While death and dying have physiological implications our reaction and how we think, feel, and behave is socially constructed. When analyzing how people express and cope with grief it is important to do so within in the context of their culture. There are entire industries and institutions that largely dominate how we perceive and respond to death in every country (Currer, 2001). The concepts of grief and mourning are seldom analyzed as social processes despite the strong influence of social factors like population characteristics, individualism, religion, social interaction, etc. (Anderson, 2001). To fully understand how and why people mourn the way they do we need to take into account the overall culture and social structures before we can start learning how to help people cope with death more effectively. By studying mourning rituals and behaviors in the context of their culture, we can identify the relationships to the larger social processes and conceptualizations of death. 
One ideal example of how a culture's perception of death is then manifested into the behaviors and rituals observed after a death is the Mexican festival, Day of the Dead. The festival itself includes many rituals, values, and beliefs that directly confront the concept of death. It also includes many specific components like social interaction, religion, tradition, etc. that have been independently associated with effective grieving (Esch \& Stefano, 2005; Koenig, Pargament, \& Perez, 2000). Further the festival is a reflection of Mexico's culture of death which is based on a familiarity and acceptance of the often times difficult subject (Brandes, 2003). This literature review will analyze how grief and mourning are manifested through Day of the Dead in the context of Mexico's culture. Both the culture and the festival continue the pattern of familiarity and acceptance of death in a relatively healthy manner.

When comparing Mexico with a country like the United States, there is a large contrast in both the culture and the rituals surrounding death. The overall culture of death in the US is built on fear and avoidance. This is partially due to how Americans have deeply institutionalized the process of death, dying and mourning (Byrne, 2000). Which has resulted in this culture of avoidance in which the subject of death is taboo. This current social conceptualization of death continues the premise that death is unfamiliar and scary, this has resulted in American's have a difficult time understanding and coping with grief on individual and social levels (Exley, 2010). There are increasing reports of discontent with how the industries and institutions in the US are handling death (Byrne, 2000). The rituals and behaviors that are socially permitted by Americans to mourn death are often inadequate, and come from the top down. By studying the relationship between the behavioral social norms of grieving and how death is over all 
perceived in other cultures, we can begin to understand what factors may influence the use of more effective grieving behaviors and processes.

Many aspects of Day of the Dead and Mexican culture indicate the missing or inadequate pieces of culture surrounding death in the US. Although the mourning rituals and processes must be understood in the context of their culture and not imposed on America's own culture. Because so many of the issues in the US are top-down, we can analyze how the cultural norms and beliefs influence the kind of socially accepted mourning behaviors and vice versa. Day of the Dead is a product of a culture that accepts the reality of death without the same avoidance and fear observed in America. It also serves the purpose or re-affirming and further maintaining the practical conceptualization of death in Mexico. The relationship between the concept of death and the manifestation of grief is balanced in a relatively effective manner.

The majority of the existing literature on bereavement in sociology comes from western perspectives. The field of research has only gained increased interest in the last 10 to 15 years (Exley, 2004). This means that the current understanding and methods are steeped in the modern western values of the motivations and minds that conducted the research. This affects our ability to share and learn about healthy coping with other cultures. Researchers from a variety of educational backgrounds are looking for new innovative ways to help individuals grieve death. There is much excitement in discovering the next big therapy, whether it be through physiological means like shock therapy or other more emotional focused means (Anderson, 2001; Hockey \& Small, 2001). However the existing mourning processes and resources need to be analyzed in the context of the larger social influences like culture. We 
need to step back and analyze how death and grief are perceived on social levels, if we wish to improve how individuals respond and cope with it.

\section{Reflexive Statement}

I have experienced more death in the last 2 years of my life than ever before, of course this peaked my interest in how people talk and behave concerning death. While I desperately clung to every word I read in hopes of finding effective grieving methods and resources, I discovered I already had many of the tools to help my family and myself. I was taking several sociological courses on death, dying, health, religion, and illness and began to focus on the larger picture of death. As I learned more about grief, mourning, and death I tried to apply them in real life with my own family. After writing a research paper on Day of the Dead, I made the realization that the effective grieving methods and processes I had researched are present in the Festival. Here was this tangible yearly event that involved all the resources and processes I had been reading about, they weren't simply included -they were presented in a celebratory manner.

I wanted to have access to both the experience and benefits. As I tried to plan a way to bring some of the concepts and rituals into my own mourning process, I began to realize the cultural contingency. Day of the Dead is an elaborate festival, it involves a significant investment of not only time and money but emotionally and mentally. There has to be a lot of cultured motivation and meaning for such an extensive event to be pulled off on such large social level. I do not come from a Hispanic background, although I come from a religious background and face the reality of death like every other human. People who celebrate and benefit from Day of the Dead have been socialized in a culture that permits those kinds of 
mental/behavioral process. If we want to analyze and learn from Day of the Dead, then we must also acknowledge the culture and history that has allowed and encouraged its creation. The recognition of social support, religion, and confrontation of death are more than observable behaviors of Day of the Dead. It is the values, beliefs and norms behind the behaviors that I intend on drawing focus back into the current discourse of death and grief. There are many existing beneficial and practical grieving resources and mechanisms like Day of the Dead that are being overlooked and undervalued. The cause of the this is extremely complex as it is intertwined in our western valued American social structure. If there is anything I have learned in my time as a college student, it is that much of the issues discussed in Sociology are deeply rooted in our social structural system. While it is daunting, and can often require the complex theories and techniques, it doesn't have to be the only solution. Day of the dead is a great example of an existing resource that is built on a cultures conceptualization of death, and collaterally is really beneficial to the mourning process. When studying culture specific events, we must analyze the culture itself if we want to learn and potentially adopt certain aspects into our own cultured mourning process.

In comparing Mexico and the United States we can see a lot of contrast in demographics, history, culture, etc. despite them being neighboring countries on the same continent of North America. This contrast continues into the subject of grieving, which is not at all surprising when we analyze the various differences between the countries that directly affect the expression and perceptions of grieving death. Things like religion, history, and institutionalization leave significant impressions in culture that collaterally influence how people think, feel, and behave in regards to death. Day of the Dead is a religious historic festival 
that is widely celebrated in Mexico. The yearly event has an emphasis of social interaction and religious spirituality, as friends and family come together to honor and remember deceased loved ones. It is events like this that present many effective grieving opportunities and resources that we should take note of. Day of the dead is very successful in its country, it is a product of their culture and the focus of analysis should encompass both.

\section{Conceptualizing Mourning:}

\section{Definitions}

Grief can be characterized by the pain and suffering we experience after a loss. Whereas mourning is the period after the loss in which the internal and external symptoms of grief are expressed (Small, 2001). The experience of emotional disturbance -or grief is nearly universal, however the expression of grief varies culture to culture (Currer, 2001). To help better analyze grief, we can view it as a kind of illness. There are the physical, mental, and emotional symptoms -only they result from a death instead of a disease. There is also the existence of cultural and social prescriptions that influence or guide people's mental and behavioral response to the grief. The mourning period is like a sickness period in that society accepts a change in behavior for a certain amount of time. Sociologists and Anthropologists have observed and analyzed death as a ritualized event, but the analysis of grief as a socially constructed process is not nearly as established (Anderson, 2001). Comparing the sick role and the mourning process allows us to draw parallels between the existing literature. We can make new connections that would otherwise may not have been possible due to the overall lack of research on socially constructed grief. 
Sick Role

A famous sociologist, Parson coined the term 'Sick role' to describe the change in expectations and perceptions of social roles, while sick with an illness. When a person is sick they are allowed to withdrawal from being a productive member of society to regain their strength and health, but only for a specific period of time (Varul, 2010). This is all built on the premise of the social roles an individual takes on, whether that be a student, a parent, and employee, etc. The sick role allows a person to at least partially withdrawal from these social roles in order to regain their health. There are 3 criteria for a person to take on the social role of being sick without any negative social response. First is the perception that the sickness is beyond their control, they are a victim. The second is being exempt from their normal daily responsibilities and roles. Finally the third deems that if the illness is severe enough the person should seek assistance or guidance from an institutionalized health service agency (Parsons, 1975). Although the third criteria stems from the western concept of seeking 'help' as an individual, most cultures still have the expectation that effort should be made to recover from illness and return back to the usual social role and responsibilities (Byrne, 2000). The sick role is strictly a transitional one as it is dependent on the physical symptoms, and socially determined period of time for which an individual can remain in the role without negative social consequences.

Certain illnesses socially qualify for longer duration and increasingly abnormal behaviors while in the sick role (Varul, 2010). A person suffering from the common cold will likely not be offered the same sympathy as someone who has stage 3 leukemia. The same can be said for grieving, the social expectations of someone coping with the death of their cat will most likely 
deeply contrast with the loss of a parent or child. The greater a loss a person suffers, the more they can socially deviate from the norm. There are social expectations of a person in mourning to not outwardly express too much nor too little, as this can result in negative feedback from others in their social networks. This is called 'emotional policing' it is the process of people regulating their emotions to fit in with the social norms (Hockey \& Small, 2001). The social norms of grieving in a particular society or culture contribute to the policing of emotions during the mourning period. In some cultures it is not socially acceptable to grieve for an extended duration of time or too outward expressively, regardless if the individual needs it. This can potentially hinder a person from coping effectively with death. On the other hand, emotional policing can be a positive influence as it offers social guidance on expressing grief both behaviorally and emotionally. Without the optimal balance of social influence and norms the expression of grief can be disorienting and/or confusing (Hockey \& Small, 2001).

To view mourning as a kind of social role makes it easier for us to conceptualize and draw parallels from existing research on the sick role. However making this connection may further contribute to the American perspective that grief, much alike illness, is bad and needs to be rid of as soon as possible. While people should process the loss a loved one, the grief we feel is only natural and should not simply be dismissed as a temporary illness (Currer, 2001). It is because assumptions like this that the differences between illness and grief should be clearly highlighted. The completion and resolution of exiting the sick role suggests that there is an end point for feelings of grief, and for the most part leaves us unchanged. When in fact there is personal growth and development that occurs while processing grief, which is not necessarily the same with recovering from an illness (Small, 2001). We do not always continue life the 
same way after a death as we do after getting over a cold or pneumonia. The impact of a death is generally much greater and longer lasting than being sick. The purpose of comparing the sick role and mourning is to highlight the societal expectations and the influence it has on the expression of grief.

Rite of Passage

Many psychologists and sociologists have theorized the process of mourning into tasks or steps. This breaks down the components of grieving into steps in which a person would complete, to overcome or resolve their grief and hypothetically shed their mourning role. Often times with the stage/task models of grief it is implied that there is a fixed end-point. The mourning process is more independently diverse and abstract, than simply going through each stage and cutting ties with one's grief (Anderson, 2001). Within the field of counselling, grief is considered problematic when it interferes with daily responsibilities, in which it should promptly be worked through. If grief is left unaddressed it can affect us pathologically. The goal is to help people work through their grief in a way that is neither too abrupt and insufficient, nor too long which can be socially perceived as morbid (Small, 2001). The ability to process grief and return to the usual responsibilities is a social expectation, and it is to be done in a reasonable (culturally relative) amount of time. The social perception is that a person cannot be a contributing productive member of society while in the mourning role. We shed the role of being sick once we are healthy again -the same goes for grieving, to be normal you must 'finish' or 'recover' from the grief and thus exit the mourning role.

Anthropologically speaking, the actual process of mourning can be better viewed as rite of passage. Using this lens we can better capture the role changes, growth/development, and 
the fluid ending of grief a person goes through while mourning. Hunter (2008:155) defines this

as:

A rite of passage is a series of culturally constructed rituals designed to conduct an individual (or group) from one social state or status to another, thereby effecting transformation both in society's perceptions of the individual and in the individual's perception of him- or herself.

There are 3 principle stages of a rite of passage, the first is the separation of an individual from their usual social state, in the context of grief this would be the adoption of the mourning role. Next is a transitional period where they are not who they were before nor who they will become. They need to process their new responsibilities and social identity, perhaps as a widow or an orphan. Finally, they reintegrate back into society by shedding the mourning role, equipped the new personal growth and development as perceived by society and him or herself (Hunter, 2008). Conceptualizing the mourning process as a kind of rite of passage sets a general framework of how people take on the mourning role while processing their grief, and then shed that role and transition back into society and life without the deceased person. How we conceptualize grief and mourning in clinical and other professional settings influences how society perceives and responds to it.

A person's culture and social networks influence almost every aspect of the rite of passage and expectations of the mourning role. Will there be a lot of communal proceedings? Can they grieve in public? How long can they mourn for? This all largely depends on the culture's values, beliefs, attitudes, and behavioral expectations. While there will always be some individuality in grieving, the social structure will play a major influencer in how grief is expressed. It is not necessarily a controlling oppressive force because culture is something humans share with each other. Without the customs and rituals there would be no guide for 
how to act, or occasions for people to share their similar experiences and bonds together. To help people cope more effectively we need to look inside their culture, to see what is enabling them -or in many cases what is hindering them.

\section{Effective Grieving}

The idea of there being some universal 10 step program or perfect guide to grieving sounds too good to be true, and it is. Because culture plays such a dominant role in grieving, it is impossible to create a one-size fits all mourning plan. A practice in one country that expresses grief might be offensive or inappropriate in another and could potentially cause further distress. Instead we can analyze various sociological variables related to health and apply them to the grieving process, being culturally as sensitive as possible. A common perception of grief is that it's unhealthy or bad. Grief is a natural response to a stressful event however, it is important to address grief and how it's being expressed to avoid additional mental and/or physical issues. The methods of expression or lack thereof can directly/indirectly lead to unhealthy behaviors and lifestyles (Anderson, 2001). It is important to address potential issues and inadequacies in the mourning process to avoid additional distress in the already stressful experience of the death of a loved one.

Two general but important sociological variables that largely contribute to a person's health are having the resources to manage the demands of life, and the consistence of control and autonomy over one's life (Currer, 2001). The death of a loved one posits a threat towards both of these factors. Death is the ultimate human limitation, and while we have made major medical advances towards sustaining life, we cannot control death. Small (2001:42) elaborates 
the toll a death can take on a person:

The death of someone close to us takes us, as individuals, to a place that exists at the brink of the crisis of modernity. We are not in control, we do not understand. Our sense of self, our relations with others, even the way we experience time is challenged.

For a lot of people, this loss of power and control really disrupts their well-being, and the resources they have to help recover from such a disruption are vital. While instrumental resources like time and money can directly/indirectly improve a person's experience with grief, arguably one of the most important resources remains social support (Brelsford et al., 2015).

\section{Social Support}

Humans are social animals by nature, so it should not come as a surprise that one of the best resources we can use in times of hardship is each other. When we are in a group we shift our thinking as individuals over to being a member of a group. The foundation of our behavior also shifts from our own personal beliefs and attitudes to align with group norms. This results in emotional policing discussed earlier, but also results in collectively shared emotions. It is in social contexts like this that societal beliefs and values can be re-affirmed and celebrated (Hopkins, 2015). Members of a group can give and receive social support from a variety of contexts ranging anywhere from a neighborhood, or school, to an entire town. The general idea is that by interacting with other members of your group, it can help reduce negative emotions and promote positive ones. There is also the actual physical resources people can offer each other such as meals, money, help with daily tasks, and other responsibilities (Brelsford et al. 2015). Social support from a group, regardless of their formality can benefit us physically, mentally, and emotionally (Esch \& Stefano, 2005). Whether the social support is through feeling 
supported or more instrumental means it is an accessible diverse resource that can be found in many of the existing social networks in a person's life.

The power of social interaction should not be underestimated, it can be very influential even on a unintentional or subconscious level. While there are many specific characteristics that can increase the effectiveness of the felt and perceived support, researchers have acknowledged that the sheer ability to interact with peers can be quite influential on emotions (Paturel, 2012). One of the most noteworthy characteristics of a crowd is the intense passion that can be observed and felt. Researchers have long been studying this feature and have coined the term collective effervescence to describe the shared emotionality of crowds. It results in people becoming more comfortable with each other, the physical and social distance is reduced, and a higher sense of intimacy. The overwhelming collective emotion is emphasized by the extent to which members share similar identities (Hopkins et al., 2015). Collective effervescence can happen in a number of social gatherings ranging from concerts, to political rallies, and religious events. Even just being a member of a group can have a positive impact on a person's self-image and esteem (Brelsford et al., 2015). To recognize and intentionally utilize such an accessible influential resource is an invaluable for both researchers and clinicians.

The use of group therapy in formal settings is becoming increasingly popular largely due to the increasing amounts of empirical research that substantiate the benefits of social support (Paturel, 2012). Many modern stress-management techniques also include social support components by taking part in group activities and/or talking in group settings (Esch \& Stefano, 2005). A common way researchers refer to the resource of social support is as social capital, a community-level resource rooted in the relationships of social networks, norms, and trust. 
Social capital is based off the economic term capital and can be viewed as the social investments people make in their communities both formal and informal. It is the product of social interaction, the more time/energy you invest into those relationships/groups the more you can benefit from them (Cockerham, 2013). Seeing as people in every culture are members of multiple groups at any given point in time, group support is a relatively accessible resource and it does not have to be in formal professional setting. Receiving social support for grieving from a person's social networks is partially contingent on whether they fit the criteria of the mourning role.

There have been many recent studies to determine what specific variables can increase the benefits of social support. The most effective groups have members that share a common identity and a sense of shared purpose (Paturel, 2012). An important product of social support among those with shared identities and values is the recognition a person feels while talking and listening to others about their experiences. Recognition among peers can lead to the idea that one's emotions are less scary and even become easier to discuss in the future (Henoch, Berg, \& Benkel, 2016). The felt support is achieved by inducing feelings of compassion and connectedness (Esch \& Stefano, 2005), while decreasing feelings of alienation and isolation, as well as reducing perceived stigma that can arise from their specific situation (Paturel, 2012). It is apparent that social support is a valuable resource and can be used for many reasons, but it what makes it so special is that social support is ubiquitous. A person can receive social support from any/all the groups they are involved in, with relatively low maintenance. Often times it is used without the knowledge of the specific benefits. Although social support should be recognized as an effective resource in the mourning process. 
Social support in times of grieving is generally expected, though in some cultures it is less likely for people to grieve publically and inform others of their situation. This can consequently end with them missing out on an important opportunity of support in the mourning process. In times of struggle reaching out to others can strengthen and improve the existing social bonds between people (Paturel, 2012). Social support or lack thereof is evident in many studies to be specifically influential in the mourning process (Brelsford et al., 2015;

Currer, 2001; Paturel, 2012). The use of social support in times of hardship not only promotes self-esteem, but it also deceases levels of stress and even protect against further mental/physical deterioration (Brelsford et al., 2015). Further, by bringing people who have had similar experiences with grieving death can promote those feelings and emotions of recognition. The death of a loved one is a very traumatic and alienating experience, relating to others through shared emotions and stories can be very comforting. While everyone will face the reality of losing a loved one, their individual experience will vary and it can soothing to be around those who have faced similar challenges.

\section{Religion}

Religion -or at least spirituality is arguably as old as human kind. With the unique human ability of consciousness we as both a society and as individuals often yearn to understand things on a deeper, more complex level. Often times people turn to religion for the answers they cannot find themselves. As science has become a dominating institution in many societies, there has been a growing divide with religion as many of the major pillars of the institutions conflict with each other. But there is a science to religion especially in terms of death and dying. Religious communities are like breeding grounds for coping resources, as they are built on 
longstanding social relationships that share beliefs, values, and traditions. With $87 \%$ of the human population being affiliated with some kind of religious group, it is a wonder that science has not fully embraced religion as a resource more (Cheney, Hughes, \& Maselko, 2011). Religion presents a context in which people can rely on the beliefs, traditions, and each other to help aid in the grieving process. There are numerous religions with different theologies and practices, religions can even vary within the different cultures. What we are left with is an ample number of rituals, traditions, beliefs, and ultimately potentially effective resources to help people effectively grieve.

According to Koenig, Pargament, and Perez (2000), religion provides 5 key functions for its members. The first is meaning, people search for deeper meaning in various aspects of their lives and rely on their religion to give them this understanding, interpretation, and general framework to live by. The second is control, when pushed out of their personal control or comfort, religion has many physical and mental resources that can help restore a sense of control. The third function is comfort, which is based in their spirituality. A fundamental purpose of religion is to help us connect with a force bigger than ourselves, to find comfort and justification that goes beyond the individual being. The fourth function is intimacy, which we can achieve with others through the shared spirituality. Religious communities often include lots of social interaction, it is another way for humans to bond together. The final function is life transformation, religion can help people begin and/or complete life transformations such as parenthood, marriage, and death. All of these functions serve a purpose in assisting people through the mourning process. Religion can be an invaluable tool for those grieving, but it depends on their personal belief. You cannot expect the same results from a person who does 
not fully and embrace their religion.

As discussed above, social capital is a product of the social relationships between people in a group. Religious organizations present an optimal environment for social investment. One empirical study found evidence that religious social support can be especially effective as the relational ties between people in the same religious community are stronger than those in an average neighborhood (Cheney Hughes, \& Maselko, 2011). This means that religious communities can offer the same physical resources (money, meals, help with daily tasks, etc.) and potentially more powerful mental/emotional support to each other. Researchers have even started to encourage the use of spirituality and religion in counselling, therapy, and assessment settings due to the high rates of association with improved physical/mental health and lowering rates of depression (Koenig, Pargament, \& Perez, 2000). Religious organizations have been found to be a rich source of social capital due to the unique environment of shared beliefs, values, and ultimately trust (Cheney Hughes, \& Maselko, 2011). Although not everyone is a part of a religious community, the potential benefits for those who are should be formally acknowledged. The individual aspects of religious communities that are independently associated with better health-outcomes, make religious communities a potential valuable resource for both health professionals and average people.

Often times people turn to religion in times of hardship. Each religion offers its followers guidance and answers to a variety of problems through the five functions listed above. Because no one knows what happens after death it is hard to separate death from religion -or at least spirituality. Many people look to religion in answering questions about death, as the shared beliefs and religious rituals can be mentally soothing in times of mourning (Brelsford et al., 
2015). While religious social capital is a vital resource, the guidance and higher meaning is also invaluable for people coming to terms with the death of a loved one. On top of the social support, religious beliefs, and values, there is usually a set of traditions and rituals that guide the behaviors after a person has died. A person in mourning can find solace in their beliefs of what happens after death, they can find comfort in the tradition and rituals that follow a death, and lean on social support from their fellow members all wrapped in one religious ideology.

\section{Cultural Relativity}

Culture plays a dominant role in what grief expressions are expected and accepted in a society. An anthropologist Paul Rosenblatt has studied the expression of grief in over 78 different societies and concluded "There are no emotions or emotional expressions that are universally present at death. What emotions are felt, how they are expressed and how they are understood are matters of culture" (Currer, 2001:53). For the grieving variable listed above to remain effective and meaningful, they must align with the cultural values and beliefs of the individual. Day of the Dead is a prime example of culturally relative grieving because the religious rituals and social processes that occur are specific to Mexico.

When looking at a very broad classification of culture like the individualism, we can get a general expectation of the social relations and behavioral motivations in said culture. The individualism spectrum measures where the emphasis is placed on people of a culture, whether it falls on individuals or groups and the motivations that result from it (Matsumoto, 1989). When you have two different countries that score on opposite ends of the spectrum, it will not only effect the kinds of mourning customs and rituals that are practiced but the overall social expectations and judgements of expressing grief. Many of the western cultured countries tend 
to be higher on individualism and emphasize the individuals uniqueness rather than the group as a whole. A collectivistic culture like Mexico places more emphasis on social cohesion and collective goals and dependence. In the context of grief, mourning would be viewed as a collective behavior because the motivations and responsibilities come from a collective perspective.

The degree of individualism directly effects how people express grief and overall mourn death. Higher on the spectrum where uniqueness is encouraged, an individual may have more freedom in variation of expressing their grief. This is due to the wider variation of expectations and judgements that are placed on that individual. On the other hand collectivistic cultures are likely to have more restricted-ranges of emotions that can be outwardly expressed. This is again due to the more restricted range of expectations and judgements that will be subjected on an individual (Matsumoto, 1989). Individualism also effects where the responsibility is placed on grief and mourning. Cultures like the United States who are high on individualism think of grief as an individual action and as a result grief processing and therapy tends to be an individual behavior. In contrast a collectivistic culture would place responsibility on the group, which is why mourning is observed as a group behavior with lots of social interaction and support.

The availability and formality of help or assistance with mourning is often a reflection of the social structures in a culture. This means that decisions on whether to reach out for formal/informal help, it may be a more accurate reflection of the degree of individualism than the culturally prescribed mourning practices and customs (Currer, 2001). All of this relates back to the concept of emotional policing which is fueled by the expectations and judgements placed on a person by their culture. Individualism influences the range of expressive emotions, the 
range of judgements about emotions, and the expectation of reaching out for help. People will police their emotions and behaviors to fit in with the norms of their culture. Too extreme in either direction would result in additional distress, whether it is from a restrictive culture of mourning or an emotionally ambiguous one.

\section{Day of the Dead}

Day of the Dead is an annual festival that takes place across Mexico once a year. It is considered a holiday in which the dead are believed to return to earth where they will be remembered and honored by the surviving family and friends (Hunter, 2008). The festival is built on historical, cultural, and religious traditions and beliefs and involves social, creative, and religious components. Day of the Dead includes all of the effective grieving resources and processes discussed above, making it a valuable opportunity to further mourn. Even though it includes independently associated positive grieving mechanisms, Day of the Dead is culture specific. We must analyze it within the context of its culture and larger social structures. A culture-specific festival like Day of the Dead can be learned from but not imposed on other cultures and societies. While we can further analyze the independent beneficial aspects of the festival, we can also learn from the culture's approach and attitudes towards death overall.

Depending on the region the length of the festival will vary, the longest being October $28^{\text {th }}$ to the November $8^{\text {th }}$ (Avis \& Morales, 2004) and the most commonly reported, October $31^{\text {st }}$ through November $2^{\text {nd }}$ (Hunter, 2008). The Day of the Dead period consists of numerous rituals and elaborate celebrations. There is a tremendous amount of preparation before the actual event, some families start as early as a month before (Green, 1972). Decorations of 
death icons such as skulls, coffins, and skeletons will be ubiquitous. Every family will have created extensive altars which are covered in candles, pictures, and special foods to honor their loved ones (Avis \& Morales, 2004). The cemeteries are also covered in items similar to the altars and death themed decorations Green, 1972). This festival is an elaborate one, as it involves a lot physical preparation, there is large amounts of decorations and they are spread everywhere throughout the towns, making it almost impossible to escape a confrontation with death (Younoszai, 1993). Part of the ritual of Day of the Dead is in fact the decorating and preparation itself. It brings a lot of color and symbolism of death into the festival.

After the festival has begun there is a lot of activity involving both formal rituals like mass and informal rituals such as social gatherings. It is important to note the abundant amount social interaction, and the variety of contexts that it results from. Masses are held almost daily in honor the dead, so their families can pray for them (Avis \& Morales, 2004). If priests and other religious figures are not in mass, they can be expected to be walking around cemeteries sprinkling holy water and blessing each individual grave. This process can extend even after the festival has finished due to the large number of graves. The cemeteries will play host to large numbers of people besides the religious figures. Over the next few days they will be filled with people taking part in a variety of activities including board games, eating meals, storytelling, gambling, etc. (Green, 1972). The festival is celebrated throughout the towns and cities. Both public and private spaces are decorated with death symbolism, where people can be found remembering and celebrating in all corners.

Day of the Dead has strong ties that date back to both the ancient Aztecs and Europe (Green, 1972). Younoszai (1993:71) a professor of Spanish and Latin American Studies at 
Hamline University describes the festivals religious history as it "Represents a wedding of 2 historical realities: the pre-Columbian day of the dead, and the All Souls' Day on the Catholic Calendar." It is a rather unique event as it combines characteristics and beliefs from multiple cultures and religions from different countries on separate continents. The festival even varies depending on the region, in places like the Oaxaca and Puebla-Tlaxcala there is more an emphasis on the altars (Green, 1972). In more agricultural areas like Huaquechula Day of the Dead is perceived with more of personal stake, as it takes place in a critical part of the agricultural season (Avis \& Morales, 2004). Day of the Dead has diverse origins in terms of culture and religion. The wide variety of personal and historical significance encompasses majority of the population of Mexico, adding an additional layer of meaning for those who participate.

\section{Analysis}

Day of the Dead presents an optimal context for participants to express grief and further mourn. Many independently associated variables of effective coping can be observed before, during, and after the festival. All of them are backed by religious and cultural beliefs, steeped in deeper meaning through its diverse historic roots. The sheer amount of social interaction, the religious beliefs, rituals, etc. result in the accumulation of opportunity for people to express their grief and comes to terms with their losses together. It is not only the tangible activities and psychological components that contribute to effective mourning, but the social processes, perceptions, and overall conceptualizations of death too. Day of the Dead re-affirms shared 
values and beliefs among the Mexican people, while establishing a context for them to continue to mourn without fear of negative social response.

As discussed above, the mourning role includes the opportunity and expectation to withdrawal from usual social roles and responsibilities. To cross-analyze the mourning role and Day of the Dead is difficult, because the underlying motivations for entering the mourning role deeply contrast in Mexico's cultural context. From a US perspective mourning is built on the premise that you are doing something abnormal, and should be resolved as quickly as possible (Small, 2001). Whereas during Day of the Dead everyone is mourning and expressing grief is the social norm, it is a collective behavior. There are still existing social expectations of the various methods used to express grief and the duration of time in which the festival lasts, but it is normal to think, feel, behave, talk, etc. directly about death. During the festival, everyone enters mourning role, everyone sheds the usual responsibilities and roles to mourn and honor the deceased. Even though it becomes the social norm, it still qualifies as a separate role because of the differences in social roles during and after the festival. The mourning role in its collective manifestation during Day of the Dead is uniquely beneficial as it includes social cohesion and interaction as additional criteria. This decreased some of the potential negative stigma as it is the literally the social norm.

As discussed above, the mourning process can be analyzed as a rite of passage. Day of the Dead helps facilitate people enter the mourning role, through the transformational stage, and then reintegrate back into society. In reviewing the criteria of a rite of passage in the context of the festival it not only fits the definition, but has the additional benefit of repetition. Although rite of passages are often only one-time events, they can occur annually like Day of 
the Dead does. The first stage in the rite of passage of the festival is to take on a new role, some people begin to prepare weeks in advance, others may begin on the first day by taking part in rituals. Either way the person can be exempt from the usual roles and responsibilities by the norms of the mourning role. Next a person enters the transformational stage, during Day of the Dead it is believed that living members are acting as hosts for the souls returning to earth. This role is maintained for the duration of the festival, and is manifested through participating in the various rituals. Even the physical spaces take on new meaning, the cemeteries become a place of celebration and social gatherings. Finally upon completing the rite of passage community members resume their previous social roles and responsibilities, having undergone growth and development. It is not to say that a person will come out the other end in the same position and mindset every year, they are still building on the memories and experiences of the previous year.

The annual occurrence is a positive characteristic in the rite of passage of Day of the Dead. The mourning role is also unique in this context as people can re-enter the mourning role yearly, instead of it being a one-time post death period. Cutting ties and letting go of the deceased is a common western expectation in the mourning process, one that can result in insufficient grieving (Small, 2001). Rituals that occur later in the mourning process are still a missing piece in western culture, where the acceptance of outward expression of grief generally ends after the funeral service (Hunter, 2008). To have such an elaborate event all for the purpose of grieving and honoring the deceased, nonetheless every year would be quite an addition to the mourning process. Day of the Dead presents an optimal context to further extend the mourning process. It is a practical occasion for people to continue to grieve 
together, they can do this every year without the fear of negative social response. On top of this there is the accumulation of growth and development that occurs in the final stage of the annual rite of passage.

Day of the dead is comprised of many rituals and traditions, that can be traced back to a variety of historical origins. Each year community members start preparing for the next festival with memories and knowledge of the previous year's festival. The traditions and customs have been passed down from generation to generation. There are special foods, deserts, and candies many are death icons like candy coffins and skulls. There are special masses, stories, games, and parades that take place all throughout the towns during the festival. These rituals can be conducted in larger social contexts and/or family specific. Day of the Dead is considered a Holiday, it is built on the beliefs and behaviors of the generations before them. People can find comfort in the familiarity and guidance these grieving-related rituals and traditions that have been passed down for decades.

Nearly every aspect of Day of the Dead involves social interaction, people coming together in order to prepare, celebrate, honor, and grieve. As discussed above when you have people that have a shared purpose and similar identity it becomes an optimal resource of social capital. Participants have similar beliefs and goals; they want to create the altars, decorate, cook traditional foods to remember, honor, and celebrate something they all have in common -the deceased. This holiday takes place on all the social levels and includes nearly all of a person's social networks, it is nearly impossible to avoid when it is celebrated so ubiquitously in certain communities. Everyone is emotionally, mentally, and physically invested in the same beliefs and goals. When you have such a unique powerful social context like this, it can often 
result in the psychological feelings and benefits of collective effervescence. This allows community members to come together to re-affirm and celebrate their values (Hopkins et al., 2015). There are so many events that members can experience collective effervescence whether it is at mass, or a large gathering in the cemetery, it is the optimal climate for overwhelming collective emotions.

The power of social interaction is amplified when looking at some of the rituals that involve people who have faced the same specific death-related events. For example, certain days are said to represents the souls returning from a specific kind of death. There is a day for those who have passed by accidents, children, and then all souls day on the $2^{\text {nd }}$ of November which include adults. A mass is held the morning of the children's souls returning, in which a candle is lit for each lost soul (Green, 1972). It is the gathering of people who have suffered similar losses which can ignite those valuable feelings of recognition to help them heal further. The contextspecific rituals where people come together to mourn their similar experiences, is a kind of form of group therapy. Especially considering many of these rituals are built on existing similar identities and religious beliefs, which can amplify the potential benefits of social interaction.

Day of the dead is a prime example of how religion can act as a guide in navigating difficult experiences such as mourning the loss of a loved one. It is a rather unique example due to the melting pot of values and beliefs from 2 separate religious origins, the ancient Aztecs and the Catholic church. As the 2 theologies have merged over the years we are left with an additional post-funeral ritual that is a reflection of both religions and the regional culture. Day of the Dead provides specific beliefs that the deceased are returning to earth, it acts as a behavioral guide through the various rituals, and it reflects the cultural values relating to death. 
On top of this the festival is backed by religious authorities. Priests and other figures are actively involved throughout the entire festival and even after to ensure each grave gets blessed. This helps to further validate the meaning behind the various rituals and beliefs, that occur during Day of the Dead.

The involvement of religion in this festival can emphasize all the other grieving mechanisms discussed above. Community members may share identities on multiple levels, and the recognition among those members further strengthen existing bonds and religious social capital. There is the general social relationships (family, friend, neighbor, etc.), then include the relational layer of shared faith, on top of the shared experience of grief. The church even gives the opportunity for them to be around others who have suffered specific similar tragedies. It is layer upon layer of shared identities that are supported by common beliefs, values, and experiences. As stated above the potential of social capital is even greater in religious communities. It is not to say that everyone who participates in Day of the Dead is a practicing Catholic, but it certainly helps in terms of effective grieving to be share in that religious identity. If you remove the religious membership and beliefs, it removes a shared connection, certain rituals, and ultimately it removes some of the meaning behind Day of the Dead.

Although determining directionality is difficult, Day of the Dead contributes and influences the overall social perceptions and culture of death in Mexico. Contrarily, the culture and beliefs influence the kind of behavior and rituals that are socially accepted. Although religion is a large contributing factor, Day of the Dead is not strictly a religious holiday because it also includes other historical and cultural influences. Even the religious aspect of Day of the 
Dead is culture specific, as many other catholic majority societies do not celebrate the same exact festival. Day of the Dead is the result of culture, religion, and history all merging together and reflecting the death ethos of Mexico. This means that Day of the Dead is an optimal blend of values, beliefs, attitudes, and behaviors that specific to the culture and history of Mexico. While Day of the Dead is an exemplary manifestation of effective grieving mechanisms, a lot of the effectiveness come from the social conceptualizations and perceptions of both death and grieving in Mexico. There are a large number of practicing Catholics in the United States, however the festival is not nearly as popular nor celebrated. Many American Catholics may reject the concept and rituals, because it does not align with their cultural values and norms. Mexican-American participants can still celebrate Day of the Dead but it is unlikely to be as elaborate, because the social norms and traditions are different in America. It really comes down to a person's perspective, socialization, and of course their geographical location. If they do not share the values, beliefs, culture, social norms, etc. then there would be no meaning behind the festival. Even if they do share them, you cannot expect the same physical/behavioral investment in a country that does not share the same history and traditions. Without being emotionally and mentally invested into an event, where it is socially accepted and widely celebrated, it would simply be nothing more than entertainment. Day of the Dead represents this well-balanced relationship of conceptualization and manifestation of mourning, that is widely shared on all the social levels. Overall it is an effective grieving resource, that is socially accepted, backed by popular religious beliefs, and involves a significant amount of social interaction. 
Mexican Culture of Death

All of the beneficial grieving mechanisms in Day of the Dead can be tied back to at least one aspect of Mexican culture. There is so much history and tradition that is interwoven into the festival itself, which contributes to the success and meaning behind it. The social norms, values, and beliefs of Mexican culture, has helped shape and continue Day of the Dead. To back up and study the wider social structure beyond Day of the Dead is necessary to understand its benefits and success in the first place. Mexico is overall a lot more accepting of the concept of death, and in turn have a more direct relationship with death. It is not hidden or viewed as a taboo subject like it is in the United States (Brandes, 2003). It is not to say that Mexico as a country mourns more better than others, but the social norms permit more opportunities to grieve effectively, often, and with more social interaction.

\section{Population Characteristics}

The people who make up a society can inform how subjects like death will be socialized. Population demographics are a part of the social structure, the realities of each characteristic have different relationships and perceptions surrounding death. The subcultures and experiences of each demographic feed into the death culture of the entire population (Moore, 1971). In Mexico many people deal with death more often and directly, the physical and emotional realities influence how death and grief are conceptualized. This results in a standard where death is more familiar and accepted. Overall death is dealt with more directly which influences how people respond to death, so the expression of grief also tends to be more direct. 
One very influential characteristic of Mexico's population is the rural communities, Mexico by many standards is still very much a rural country (Younoszai, 1993). It is in these nonurban communities where death is likely to be a common reality, it is just a part of nature running its course. They are also less likely to have access to the same medical professional resources as urban communities. Having direct hands-on experiences with death can certainly increase the exposure and in turn the familiarity of it. The high percentage of rural populations who deal with death more closely and consistently contribute and reinforce the increased acceptance in Mexican culture (Brandes, 2003).

Another influential demographic is the large population of children and adolescence. Quite a large percentage of people living in Mexico are below the age of 15-years-old (Younoszai, 1993). This means in general terms that a large percentage of their population are still quite immature and impressionable. To study youth cross-sectionally with other demographics that produce familiarity and/or acceptance of death, presents a context with further exposure and acceptance. Though it may be a product of innocent ignorance, it still contributes to the main stream culture of death nonetheless. We can also observe the transfer of these beliefs and attitudes about death to children during Day of the Dead. The toy and candies are consistent with the death theme of the festival, they do not hide depictions or facts of death in the presence of children. Children are just as participatory as everyone else, the concept of death is not hidden or reduced in spite of them (Green, 1972). The youth in Mexico accept the direct confrontation and reality of death as it is a part of the culture, death can be as familiar as birth. 
A third contributing demographic of Mexico's population is the amount of people living at or below the poverty line. Entire communities live in poverty with the constant threat of malnutrition, injury, and overall poor healthcare (Younoszai, 1993). The extremely poor are exposed to the threat of death daily. Whether it is their own death or that of another, they have much higher rates of exposure to death than others. It is not that they do not feel grief or fear death, but it is a frequent reality for them and in turn are also more accepting of it (Moore, 1971).

The fourth influential demographic is the majority religion Catholicism, which is an extremely important institution in Mexico. As discussed above religion has its own beliefs, values, and attitudes surrounding death. The mental, emotional, and behavioral guidance religion offers is something many people find comfort in. Specific to Mexico's population religion tends to be even more amplified among rural, poor, and youth communities (Younoszai, 1993). All of these major demographics have the frequency and/or familiarity with death in common. Then to overlap these as they so often do, a person who lives in a poor, rural, religious community with many younger members would face the reality of death so often and directly that naturally it would become increasingly familiar and in turn accepting of the inevitable reality.

History and Norms

Death was a subject of great importance and emphasis among the ancient Aztecs who lived in Mexico long before was a country. It is evident in their rituals, symbols, language, and murals. When the Spanish colonizers first encountered the Aztecs they were shocked by the explicit obsession of blood, gore, and death (Younoszai, 1993). Ironically when the Spanish 
colonizers caused death on a mass level through foreign sickness and war, it only amplified the focus of death. Historians have argued that it was the high rate of death in the early years of Spanish/Aztec interaction, that led to cultures of death merging and expanding. The Aztecs had an established familiarity with death that continued even after colonization. The Spanish brought with them the Catholic religion and relatively speaking modern perspective, which slowly developed into the culture of death today (Moore, 1971). Both historical origins support the current premise that death and grieving are generally accepted and dealt with openly. While many of the death-related traditions and rituals in Mexico conform with Catholic theology, they still contrast with those in the United States in terms of the expected duration and expression. Great importance is placed on having all friends and family members present, they are expected to make every effort to attend the ceremonies. All participants including children are active members in all aspects of the rituals. The social network of friends and family act as a united front in the face of the loss, and the existing bonds are re-strengthened (Moore, 1971). There is great significance placed on the involvement of friends and family. Social support is evident in their funeral proceedings, Day of the Dead, and Mexican culture of death overall.

The general rituals include the funeral, a ceremony at the grave site, and a wake. The entire group of people accompany the family to the grave site. Often times people stay longer walking around the graves thinking back to others who have passed and openly discussing death. In rural areas the funeral and wake are held inside the family's home, and in more urban areas the body is likely to be held at a mortuary. Regardless the setting most ceremonies include an open casket, the body is simply present. Over all the emotional response is much 
more open than a traditional funeral in the United States, outward expression is accepted and encouraged. The children are exposed to the body and sheer emotions, just the same as everyone else. This is one example of how they are socialized to accept the death and grief regardless the formality (Younoszai, 1993). The traditional catholic rituals that follow the death are similar to the US, however there is more emphasis on social support and the direct nature of death that Mexico's culture embodies.

Day of the Dead is a festival that offers additional opportunities to mourn in a very socially accepting way. It is important to recognize how the rituals and experiences can also influence the mainstream culture in return. It is all a part of the socialization that surrounds death and mourning. The rituals that consist of explicit confrontations with the concept of death further familiarizes the experience and reaffirms the values and beliefs of expressing grief. Day of the Dead reflects and reinforces the larger social processes and understandings. It can be a vital tool used in both coping with and socializing the concepts of death. Children witness this celebration within their social networks and learn to understand that death is normal, just like birth or weddings. The fact that these rituals are highly social events, helps people reaffirm the normalcy of death and grieving. They can celebrate their beliefs, values, and norms through events like Day of the Dead all while offering support to people who are suffering the loss of a loved one. All of this is then sealed with religious beliefs and values that are also ubiquitously shared in the main stream culture.

Although Mexico is a collective society and therefore likely to have a more restricted range of emotions that are socially permitted in the mourning role, the ones that are permitted are more outwardly expressive and direct. One could even argue that the overall mourning role 
in Mexico is less emotionally suppressive. The beliefs and attitudes surrounding death are based on the frequency and reality of it, they are widely shared among the population. It is not that they do not have expectations or judgements at all, because there is the high expectation of social interaction and outward expression. One benefit to having a more widely shared mourning role is that it can help people move through the rite of passage of mourning. The population is collective both in their social lives and their expectations of grief. This can make the process of mourning easier to recognize and navigate, as the norms, beliefs, and values are generally shared in the larger population. There are clearer expectations and norms for people to follow through the mourning process. It is even facilitated yearly by Day of the Dead, where everyone enters the mourning role together.

The Mexican perspective of death is simply more direct and accepting. This comes from a culture of history, social contexts, and rituals that have more familiarity with the subject. It is not that they are unafraid to die or do not feel intense emotions of grief, they are just more aware and open to the reality of it. This is not necessarily the result by intention, but through the history, social structure, and traditional history. Regardless, the result is a manifestation of many independent effective grieving resources, processes, and perceptions. An entire culture cannot be generalized by ignoring the experiences of individuals, but the larger social patterns offer a window into the generally accepted perceptions and practices.

\section{Discussion}

It is apparent that Day of the Dead embodies many beneficial and effective grieving processes and resources. It is also important to acknowledge how the festival is relative to the 
Mexican culture surrounding death, as it is a product of both their history and tradition. The festival serves the purpose of both re-affirming the culture's direct approach to death, and allowing members to annually mourn and honor their loved ones. It is a result of a culture who is very familiar with death, and whose values, beliefs, and social norms reflect this familiarity. The festival represents many effective psychological components and sociological processes in terms of grieving, but also the relation between the conceptualization of death and how in return it is emotionally/behaviorally manifested.

Every culture has its own observable behavioral response to death through mourning and grief. The behaviors involved in the rituals and traditions of mourning are vastly different culture to culture. As the example of Day of the Dead demonstrates, the behaviors following death even on an individual level are largely influenced by the culture itself. This is an important point to be aware of this as researchers continue to work on improving America's post-death responses and resources. Especially considering that grief and mourning is mainly processed as individuals in America. Many of the issues we are facing are top down, the overall conceptualization and response comes from our social structure. Creating a new holiday, event, or therapy where individuals are offered the opportunity to grieve will not be as effective if it is not meaningful on an individual level and shared on larger social levels. Grieving opportunities and resources must meet the needs of individuals and social expectations for them to be optimally effective.

The socially acceptable mourning roles and rites of passage in America and Mexico are observably different on all the social levels. The ambiguity and potential scrutiny people face in America as they try to navigate their way through the mourning process, is highly contrasting to 
Mexico's overall attitude and customs. So many of the positive beneficial aspects of Mexico's culture and Day of the Dead can be related back to the social cohesiveness they embody something that is lacking in America. The overall social structures are different, which makes it difficult to line up the mourning roles and processes and compare in hope of learning and applying beneficial aspects into the other. Instead we can learn from this very observation, the social structure and culture overwhelmingly influential in how people react to grief. No social structure or culture is without flaws, each has its own strengths and weaknesses. In terms of mourning, Mexico's culture and social structure is quite effective and beneficial. While Day of the Dead full of independent coping mechanisms, is also a great reflection of the structure.

\section{Limitations}

The field of grief and mourning in sociology is still relatively small, there is limited existing empirical literature on grief and mourning -nonetheless in a cultural context. Much of the research and studies are done in a clinical artificial settings, focusing on the independent effective variables. To cross-analyze the conceptualization of death and how it is in turn manifested into mourning all within the context of one culture is potentially problematic due to the possibility of generalizations. On top of this, many of the theories and data is from western perspectives, and do not always translate into other cultures seamlessly. The nature of grief has not been a big priority of the sociological and anthropological agendas, and as a result it hardly been analyzed as a social process.

\section{Future Research}

As stated above there is minimal research and literature of events like Day of the Dead. Many of the existing published literature focuses on the independent grieving mechanisms 
(creativity/group support/length/etc.) and specific theories/therapies conducted in clinical settings. Similar to the growing empirical evidence on the benefits of religion, Day of the Dead is already an established socially accepted part of society and should be recognized as an effective resource. There are many events and resources that are comparable to Day of the Dead that may embody the same beneficial aspects and reflect the larger social structures that they are a part of. Humans have been dealing with grief and mourning for hundreds and thousands of years. While social structures have changed considerably over this time, the existing resources and processes are products of that change. Instead of clinical lab research being the dominating focus in the field of grief, we should pay more attention to analyzing the existing processes and resources that help people cope with death. Resources that are steeped in history and tradition are more likely to already be socially accepted and meaningful within their culture.

A more specific future focus within Day of the Dead and mourning, is to analyze Day of the Dead outside of its country. There are many people of Mexican ethnicity who celebrate the holiday in the United States. While they may share the same values and beliefs as people who are physically in Mexico, the holiday is not as widely supported and accepted within the US. As I concluded above the social cohesion and the culture-specific institutions and structures within Mexico largely contribute to its overall effectiveness in the mourning process. Would the mourning role be as socially accepted in the US? Would the rite of passage maintain its meaning and transformational power if it was not as collectively shared and accepted? 


\section{References}

Agle, B. \& Weaver G. (2002). Religiosity and ethical behavior in organizations: A symbolic Interactionist perspective. Academy of management review, 27(1), 77-97.

Anderson, M. (2001). 'You have to get inside the person' or making grief private: image and metaphor in therapeutic reconstruction of bereavement. In Hockey, J., Katz, J., \& Small, N. Grief, Mourning, and Death Ritual (135-143). New York: Open University Press.

Avis, M. \& Morales, C. (2004). Cultural Tourism, the State, and Day of the Dead. Annals of tourism, 31(4), 879-898. doi: 10.1016/j.annals.2004.03.003

Brandes, S. (2003). Is There a Mexican View of Death? Ethos, 31(1), 127-144. doi: 10.1525/eth.2003.31.1.127

Benkel, I., Berg, C., \& Henoch, I. (2016). The shared experience help the bereavement to flow: A family support group evaluation. American Journal of Hospice \& Palliative Medicine, 33(10), 959-965.

Brelsford, G., Mondell, L., Raldiris, T., \& Ramirez, J. (2015). Stress and negative religious coping in a community sample. Journal of Psychology and Christianity, 34(2), 141-154.

Byrne, M. J. (2000). Dealing with death: Problems and responses in American funeral practice. Retrieved from UMI. (9969701)

Cheney, R., Hughes, C., \& Maselko, J. (2011). Religious social capital: Its measurement and utility in the study of the social determinants of health. Social Science and Medicine, 73, 759-767.

Cockerham, W. (2013). Social Causes of Health and Disease ( $2^{\text {nd }}$ ed.) Cambridge, UK: Polity Press.

Currer, C. (2001). Is grief an illness? Issues of theory in relation to cultural diversity and the grieving process. In Hockey, J., Katz, J., \& Small, N. Grief, Mourning, and Death Ritual (49-60). New York: Open University Press.

Esch, T. \& Stefano, G. (2005). Love Promotes Health. Neuroendocrinology Letters, 26(3), 264268.

Exley, C. (2004). Review Article: The sociology of dying, death and bereavement. Sociology of Health \& IIIness, 26(1), 110-122.

Finucane, N., McGuinness, B., \& Roberts, A. (2015). A hospice-based bereavement support group using creative arts: An exploratory study. Illness, Crisis, \& Loss, 23(4), 323-342.

Green, J. (1972). The days of the dead in Oaxaca, Mexico: An historical inquiry. Omega: Journal of death and dying, 3(3), 245-261.

Hockey, J. \& Small, N. (2001). Discourse into practice: The production of bereavement care. In Hockey, J., Katz, J., \& Small, N. Grief, Mourning, and Death Ritual (99-124). New York: Open University Press.

Hopkins, N., Khan, S., Srinivasan, N., Stevenson, C., Reicher, S., \& Tewari, S. (2015). Explaining effervescence: Investigating the relationship between shared social identity and positive experience in crowds. Cognition and Emotion, 30(1), 20-32.

Hunter, J. (2008). Bereavement: An incomplete rite of passage. Omega: Journal of death and dying, 56(2), 153-173.

Koenig, H., Pargament, K., \& Perez, L. (2000). The many methods of religious coping: 
Developmental and initial validation of the RCOPE. Journal of Clinical Psychology, 56(4), 519-543.

Matsumoto, D. (1989). Cultural influences on the perception of emotion. Journal of CrossCultural Psychology, 20(1), 92-105.

Moore, J. (1971). The Death Culture of Mexico and Mexican-Americans. Omega: Journal of death and dying, 1(4), 271-291.

Parsons, T. (1975). The sick role and the role of the physician reconsidered. Health and Society, 53(3), 257-278.

Preston, J. \& Shin, F. (2017). Spiritual experiences evoke awe through the small self in both religious and non-religious individuals. Journal of Experimental Social Psychology, 70,

Small, N. (2001). Theories of grief: A critical review. In Hockey, J., Katz, J., \& Small, N. Grief, Mourning, and Death Ritual (19-48). New York: Open University Press. 212-221.

Varul, M. (2010). Talcott Parsons, the sick role and chronic illness. Body and Society, 16(2), $72-$ 94. DOI: $10.1177 / 1357034 X 10364766$

Younoszai, B. (1993). Mexican perspectives related to death. In Irish, D., Lundquist, K., \& Nelsen, V. Ethnic variations in dying, death, and grief: Diversity in universality (pp. 6777). Philadelphia, PA: Taylor \& Francis. 